


\section{Article Artículo Paper Repensant la política de 3 serveis socials per a un canvi d'època}

\section{Xavier Pelegrí Viaña ${ }^{1}$}

\section{Resum}

En aquest article es voldria discutir alguns problemes que es consideren cabdals de cara a situar els serveis socials en el canvi d'època que s'anuncia. Hem vist com l'Estat del benestar ha patit les pitjors repercussions que ha comportat la crisi econòmica, i els serveis socials no s'han deslliurat de les mateixes limitacions que han afectat a les altres polítiques socials. La superació de la crisi sembla que no ens retornarà al punt de sortida, sinó que obligarà a reorientar el model que s'havia anat implantant en els darrers trenta-cinc anys. Per tant, lobjectiu del present text és encetar el debat de com caldria repensar la política de serveis socials dins el marc de l'Estat del benestar per fer front als nous temps que se'ns presenten. L'anàlisi, a partir de fonts secundàries, es desenvolupa a dos nivells: un de caràcter general que s'exposa en el primer apartat, gira entorn a temes irresolts del sector de serveis socials de l'estat espanyol; i un segon, més enfocat a la pràctica dels aspectes que veiem problemàtics en el sistema de serveis socials de Catalunya. En ambdues parts s'as- 
sagen conclusions proposicionals que, com tota la reflexió, s'han d'entendre obertes a la rèplica com correspon a tota exegesi científica.

Paraules clau: serveis socials, estat del benestar, universalitat, drets subjectius, organització del sistema.

\section{Resumen}

En este artículo se quisiera discutir algunos problemas que se consideran primordiales de cara a situar los servicios sociales en el cambio de época que se anuncia. Hemos visto como el Estado del bienestar ha sufrido las peores repercusiones que ha supuesto la crisis económica, y los servicios sociales no se han librado de las mismas limitaciones que han afectado a las otras políticas sociales. La superación de la crisis parece que no nos devolverá al punto de salida, sino que obligará a reorientar el modelo que se había ido implantando en los últimos treinta y cinco años. Por tanto, el objetivo del presente texto es iniciar el debate de cómo se habría de repensar la política de servicios sociales dentro del marco del Estado del bienestar para hacer frente a los nuevos tiempos que se nos presentan. El análisis, a partir de fuentes secundarias, se desarrolla en dos niveles: uno de carácter general que se expone en el primer apartado, gira en torno a temas irresueltos del sector de servicios sociales del estado español; y un segundo, más enfocado a la práctica de los aspectos que vemos problemáticos en el sistema de servicios sociales de Cataluña. En ambas partes se ensayan conclusiones proposicionales que, como toda la reflexión, deben entenderse abiertas a la réplica como corresponde a toda exégesis científica.

Palabras clave: servicios sociales, estado del bienestar, universalidad, derechos subjetivos, organización del sistema.

\footnotetext{
Abstract

In this paper I discuss some issues that are considered mandatory before placing social services in the new era is announced. We have seen how the welfare state has suffered the worst repercussions that led to the economic crisis, and social services have not been
} 
delivered to the same limitations that have affected other social policies. Overcoming the crisis does not seem to take us back to the starting point, but it will require reorienting the model that had been implemented in the last thirty-five years. Therefore, the aim of this text is to start a debate on how we should rethink the politics of social services within the framework of the welfare state to meet the new times we face. The analysis, based on secondary sources, is developed on two levels: a general as outlined in the first section focuses on unresolved issues in the social services sector in Spain; and a second, more focused on the practical aspects of the problem we see in the system of social services in Catalonia. Both parts are tested propositional conclusions, as all thought, must be seen as open to the replica corresponds to the entire scientific exegesis.

Keywords: social services, welfare state, universal, individual rights, organization of the system. 
El present article parteix de la constatació que l'Estat del benestar que s'havia anat construint d'ençà de l'establiment de la democràcia, ha patit les pitjors repercussions que ha comportat la crisi econòmica. D'aquesta i de les seqüeles que se n'han esdevingut se n'ha parlat abastament i, durant els darrers anys, hem experimentat retallades en la despesa social i, el que és pitjor, la pèrdua de drets subjectius que crèiem consolidats.

D'altra banda, com auguren molts autors, tot apunta a que la superació de la crisi no ens tornarà on estàvem sinó que donarà lloc a un "canvi d’època”. S’exposen quines causes estan contribuint a la transmutació de la societat (la globalització de l'economia, la pèrdua de legitimitat política, la irrupció de moviments alternatius i les noves tecnologies, entre d'altres) però ningú s'atreveix massa a anticipar els resultats d'aquesta mutació i, encara menys, a proposar accions per a que aquesta ens sigui propícia.

Pel que fa al conjunt de polítiques socials que hem convingut en anomenar Estat del Benestar, els pronòstics d'alguns analistes no són gaire esperançadors. Se'ns diu: “L'Estat del benestar tal i com el coneixem (és a dir, la capacitat que tenien els governs nacionals de compensar les desigualtats que suscitava la competència oberta en el mercat) serà difícil de mantenir en la seva dimensió actual” (Subirats \& Vallespín, 2015, pág. 42).

Els serveis socials, no s'han lliurat de les mateixes limitacions que han afectat a les altres polítiques socials. També ells han sofert els estralls de la crisi i els de l'austeritat que s'ha practicat escudant-se en aquella; l'afer de la renda mínima d'inserció del 2011, la moratòria i impagaments a les entitats socials o la supressió de les prestacions vinculades als serveis són algunes de les que han passat menys desapercebudes.

Si apliquem als serveis socials el pronòstic del canvi d’època, caldria saber l'orientació que demanaria aquest canvi, i més encara, com caldria preparar les estructures institucionals i tècniques per fer-lo possible. Aquest és l'ambiciós propòsit del present text: encetar el debat de com caldria replantejar la política de serveis socials dins el marc de l'Estat del benestar pels nous temps que se'ns presenten.

L'anàlisi, a partir de fonts secundàries, es desenvolupa a dos nivells: un de caràcter general que s'exposa en el primer apartat, gira entorn a temes irresolts del sector de serveis socials que poden aplicar-se al conjunt de l'estat; i un segon, que està més enfocat a la pràctica dels aspectes que veiem problemàtics en el sistema de serveis socials de Catalu- 
nya. En ambdues parts s'assagen conclusions proposicionals que, com tota la reflexió, s'ha d'entendre obert a la rèplica com correspon a tota exegesi professional.

\section{Consideracions a la naturalesa dels serveis socials}

En el procés de construcció de l'Estat de benestar espanyol, els serveis socials foren uns intrusos amb qui no es comptava i no van ésser gaire benvinguts. Recordi’s que no figuren com a tals a la Constitució del 78, que ningú els reclamà i, encara ara, poca gent sabria donar-ne raó. Gairebé no surten als mitjans de comunicació i, quan ho fan, quasi sempre és pejorativament; per tant no és d'estranyar que sigui el menys dotat financerament dels quatre pilars del benestar (Santos, 2012).

Aquesta manca de coneixement i reconeixement és deu, en bona part, a tota una sèrie de dèficits i equívocs que poden semblar anecdòtics, però són cabdals, i no han estat abordats i resolts decididament en els més de trenta-cinc anys d'existència. Són factors constituents que afecten a la pròpia naturalesa dels serveis socials i que, malgrat algú pugui pensar que la condicionen poc, són de vital importància, especialment per ressituar-los en l'espai que els correspon.

\subsection{Nivell versus sector: el repte de la universalitat}

En primer lloc caldria -d'una vegada per totes- decidir si es vol (i convé) considerar els serveis socials un sector (com l'educació i la sanitat) o bé un nivell, l'últim nivell d'atenció. Manuel Aguilar és un dels autors que més han estudiat el pas de la beneficència als serveis socials i, seguint el seu anàlisi se'n desprèn que caldria afrontar aquest repte sense més dilació (Aguilar, 2014).

Ésser un sector ${ }^{1}$ (o pilar com també se l'anomena) significaria que és universal o tendeix a la universalització, mentre que si segueix essent un nivell (l'últim nivell assistencial) suposaria atendre només el segment social més pobre prèvia demostració d’absència total

1. Aguilar conceptualitza un sector com "un àmbit de la política social delimitat a partir d'una definició del seu objecte, és a dir, del subconjunt de problemes o necessitats dels què s'ocupa [...] i per un cert model d'atenció, que inclou un conjunt específic d'eines conceptuals i tècniques i una configuració professional” (Aguilar M. , 2009, págs. 172-3) 
d'altres recursos ${ }^{2}$. L'autor argumenta que, avui per avui, els serveis socials "són un híbrid, un camp en procés de transformació des de l'antic nivell de la beneficència o l'assistència social cap a un nou sector o pilar de l'Estat de benestar" (Aguilar, 2014, pág. 19). Sobre aquesta noció de sector, pilar o rama de caràcter més natural, s'hi pot bastir un sistema que abasti tot el sector o una part d'aquest ${ }^{3}$.

Als serveis socials no els convé mantenir per més temps aquesta ambigüitat de tenir un peu a cada riba. Per a ser coneguts i reconeguts sense equívocs caldria definir l'orientació que es vol que tinguin els serveis socials: si “cuidar-se de tot per a alguns" (els pobres, com segueix pensant la majoria de la població) o "cuidar-se d'alguna cosa per a tots" (com fa la sanitat o l'educació). Ens inclinem per això segon, però sovint els fets no diuen el mateix.

Sobre la pretesa universalitat d'un sector/sistema, també es plantegen interrogants. Es tendeix a pensar que universal significa que és per tothom, sense especificar res més. Però en la pràctica constatem que es pot qualificar d'universal un sistema destinat només als que tenen la nacionalitat espanyola i als nacionals dels estats membres de la Unió Europea. Aquest és el significat que s'aplica a les lleis de serveis socials, pel que fa als serveis especialitzats. A vegades s'afegeixen els d'altres estats extracomunitaris si són residents, però sense aclarir que es tracta de tenir "permís de residència". En altres casos, es demana a les persones nouvingudes un temps d'estada. I, finalment, encara es pot trobar prestacions que seleccionen els destinataris en funció de paràmetres d'ingressos o renda. En conclusió, cal anar amb compte amb l'ús polític del llenguatge.

La universalitat d'un sistema no és res més que una declaració de principis. A les lleis, com en la de serveis socials de Catalunya, es fa servir la fórmula jurídica "titulars del dret d'accés" (art. 6) per dir que es dirigeixen a "tota la població" malgrat després s'entra a especificar quins grups comprèn. Aquest dret d'accés s'hauria de matisar al menys amb dues premisses més: a) que hi hagi una valoració tècnica que acrediti l'existència d'almenys una circumstància preestablerta com a susceptible de ser atesa pel sector; i b) que hi hagi una prestació dissenyada a l'efecte per oferir una solució plausible al fet planejat. Si manca alguna de les dues premisses, l'accés al sistema d'atenció no es pot produir.

2. Els sectors es poden imaginar com pilars verticals, mentre que el nivell correspondria al que es diu "última xarxa".

3. Aguilar defineix sistema com "el conjunt organitzat $i$ articulat d'institucions i dispositius que aspiren a respondre a un conjunt de problemes o necessitats socials” (Aguilar, 2009, pág. 173); aquesta articulació, o més aviat la seva manca, és el que porta a alguns a dubtar dels serveis socials com un veritable sistema. 


\subsection{L'objecte o bé a protegir: la delimitació dins l'àmbit del benestar}

Un segon repte que encara té pendent el sector de serveis socials és definir el seu objecte o, com prefereix dir Fantova, el bé individual que el sector promou i protegeix. Aquest autor, defensa des de fa anys que així com el sector de la sanitat procura per la salut, el d'educació facilita l'aprenentatge, el d'habitatge promou l'allotjament, el de treball fomenta l'ocupació i el de garantia d'ingressos cobreix la subsistència, als serveis socials, diu, els correspondria la interacció. Ell entén la interacció com "l'ajustament dinàmic entre autonomia funcional i integració relacional", és a dir, entre el que la persona pot fer per ella mateixa i els suports personals o socials que requereix (Fantova, 2014, pág. 120 i 213).

Altres propostes defineixen l'objecte a partir dels grans tipus de necessitats de que socupa el sector i que es podrien sintetitzar així: a) atenció a la dependència, b) protecció de persones no del tot capaces, i c) acompanyament del desenvolupament personal i la integració comunitària (Aguilar, 2013, pág. 161). Aguilar, en altres textos, n’afegeix una quarta que respondria a la cura dels menors en substitució dels pares quan estan treballant (Aguilar, 2014, pág. 29).

Fins ara no hi ha hagut consens en el sector dels serveis socials sobre com anomenar el seu objecte o camp de treball. Malgrat la dificultat que comporta trobar un mot que l'expressi fidelment, seria convenient fer l'esforç d'acordar-lo perquè això redundaria en aclarir i diferenciar aquest sector dels altres. Creiem que el concepte-objecte hauria d'acomplir tres condicions (com les trobem en altres sectors): 1) que fos comprensible col-loquialment sense necessitar d'una gran explicació tècnica; 2) que s'identifiqués amb una necessitat bàsica de tota persona, acceptada com un dret a ser cobert; i 3) que reflectís quelcom en què o sobre el qual s'hi pogués intervenir efectivament. Potser locucions com integració, desenvolupament personal o cohesió socialt complirien força els requisits proposats.

Quant als grans blocs funcionals que concentrarien l'activitat pròpia dels serveis socials, hi ha més possibilitats de consens. S’hauria d'evitar, però, caure en l'error que tant

4. Cohesió social, segons ho entén Rodríguez Cabrero, és quan un sistema procura tres objectius complementaris: 1) promoure l'autonomia i la participació social dels ciutadans; 2) crear xarxes socials e institucionals que generin capital social i afavoreixin la inclusió social; i 3) contribuir a la materialització dels drets socials en el seu sentit més ampli (Rodríguez Cabrero, 2011, pág. 9) 
Aguilar com Fantova avisen: basar la tipologia en grups de població concrets, o en mancances que correspondria cobrir a altres sectors i que no cobreixen perquè no se'ls reconeix el dret. Lobjectiu de fixar l'objecte respon a la possibilitat de clarificar la distribució de responsabilitats a càrrec de cada sector del benestar. Caldria repensar els límits i continguts de cada sector i veure si realment s'atenen tots els aspectes que concerneixen a cada sector o n'hi ha que recauen en sectors que no els tocaria.

Atenent als serveis socials, és evident que realitzen accions que correspondrien -stricto sensu- a altres sectors, sobretot els de manteniment de la renda (prestacions finalistes), i en menor mesura, potser els d'habitatge i treball. El sistema de serveis socials a Catalunya ${ }^{5}$ és l'àmbit, després de l'administració de l'estat, que més prestacions econòmiques concedeix (Generalitat de Catalunya, 2015, pág. 20), i això sense comptar la Renda Mínima d'Inserció que consta al Departament d'Empresa i Ocupació, tot i estar estretament vincula als serveis socials. Aquestes prestacions (o al menys aquesta última) haurien de passar a ser assumides pel sector de garantia de rendes segons la proposta d'Aguilar i de Fantova ${ }^{6}$.

\subsection{Drets socials: subjectius i garantits}

El tema dels drets socials està íntimament vinculat a la qüestió que hem tractat a l'apartat a) sobre a qui es dirigeix un determinat sector o sistema de l'estat del benestar. E1 dret (segons l'accepció que aquí ens interessa) és la "facultat d'exigir allò que ens és degut, [...] de tenir, exigir, usar, etc., allò que la llei o l'autoritat estableix a favor nostre o ens és

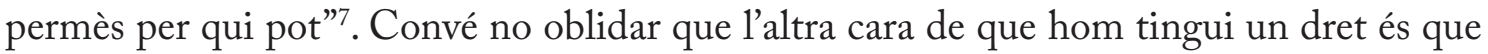
algú altre tingui el deure d'assegurar que es pugui exercir.

L'atorgament dels drets requereix d'una norma que ho reconegui. Això és especialment rellevant en els drets socials que, bàsicament, són drets prestacionals; és a dir, que generen obligacions positives de fer quelcom, en contrast amb els drets civils i polítics que tendeixen a generar obligacions negatives, d'abstenir-se per preservar la llibertat dels

5. Sota competència del Departament de Benestar Social i Família.

6. La manera de garantir la subsistència amb múltiples prestacions desconnectades cada dia és més criticada i surten opinions expertes que advoquen per crear una Renda Garantida de Ciutadania o un Mínim Vital Garantit, alguns, com a primer pas cap a una Renda Bàsica de caràcter universal.

7. Diccionari de la llengua catalana (2a edició) de l'Institut d'Estudis Catalans. 
individus $^{8}$ (Añon \& García, 2004, pág. 61). De fet, mentre els drets fonamentals ja queden reconeguts en la Constitució Espanyola $(\mathrm{CE})$, els socials requereixen de lleis específiques que els concretin.

Donada la distribució competencial que fa la $\mathrm{CE}$, dels sis sistemes clàssics que conformen l'Estat del benestar, només els serveis socials són de competència exclusiva de les comunitats autònomes. Per tant, han de ser les lleis autonòmiques les que estableixin el nivell de drets que vulguin atorgar. El model de descentralització territorial de l'Estat comporta aquestes llibertats igual que també suposa certs gravàmens. Des d'aquesta òptica, no té massa sentit que es reivindiquin mesures d'homogeneïtzació a l'administració estatal via article 150.3 de la $\mathrm{CE}$ com s'ha fet des d'algunes instàncies. Entenem que els drets socials relatius als serveis socials haurien de desplegar-se per la normativa pròpia de cada un dels 17 sistemes de serveis socials. Per això, partir de 2006, veiem com les lleis autonòmiques comencen a establir algunes prestacions com a drets subjectius sense necessitat de mandats estatals.

Vilà especifica que, perquè existeixi un dret subjectiu, s'han de donar quatre condicions: a) definició clara de la prestació i del seu contingut; b) concreció de les condicions personals o d'altra índole que es requereixin per a l'accés a la prestació; c) garantia de provisió dels recursos necessaris i del finançament suficient; d) possibilitat, si fos vulnerat el dret reconegut, de recórrer per via administrativa i judicial (Vilà, 2011, pág. 112). Els dos últims requisits són els que han d’oferir la garantia de la realització material i el de la defensa deguda front l'incompliment.

El que s'ha succeit en els darrers anys és que, drets subjectius que havien estat reconeguts normativament, no s'han garantit a nivell institucional ni s'han defensat a nivell jurisdiccional. És a dir "els governs han començat a vincular l'acompliment dels drets subjectius als fons pressupostaris. Dit d'una altra manera: els drets garantits per les lleis queden condicionats a si hi ha o no diners en la caixa comú” (Subirats \& Vallespín, 2015, pág. 43).

A més, tampoc s'ha contraposat per part de les persones afectades, la legítima reclamació via jurisdiccional dels drets incomplerts, suposadament per les dificultats d'em-

8. Tot i això, s'acostuma a relativitzar que els drets civils o polítics no requereixin d'algun tipus d'intervenció dels poders públics, al igual que no hi pugui haver drets socials guiats per obligacions negatives dels poders públics. 
prendre aquest acció. I és que malgrat "la força normativa dels drets socials il·legalitza tota intervenció legislativa que suposi la supressió arbitrària o la desatenció grollera de bens i serveis ja prestats [...] [els ordenaments jurídics] ofereixen possibilitats desiguals a l'hora de plantejar llur protecció front la jurisdicció" (Añon \& García, 2004, pág. 69).

Dit d'una altra manera, hi ha instal-lada la concepció que l'exigència a nivell judicial d'un dret subjectiu és inviable si l'administració que l'hauria de proveir al·lega la impossibilitat material satisfer-lo. Els tribunals no tenen força coactiva suficient front l'autonomia de les administracions per condicionar la disponibilitat de les prestacions (sobretot quan impliquen recursos estructurals inexistents) ni l'establiment de prioritats pressupostàries.

\section{Replantejaments del sistema públic}

Plantejats els reptes pendents del sector de serveis socials a nivell de l'Estat que acabem d'exposar, ara ens situem a escala autonòmica, concretament a Catalunya, i més a nivell del sistema ${ }^{9}$ de serveis socials. Així com diu Santos que: "si no hi ha objecte no hi ha sistema" (2012, pág. 112), també podríem afegir que sense delimitar un sector de competència d'abast universal i sense garantir uns drets subjectius, tampoc hi ha un veritable sistema.

Seguidament exposem els tres paràmetres que hem seleccionat (entre tants altres que podríem incloure) perquè els considerem crucials per tal de donar el sentit i l'impuls que requeririen els serveis socials de la nova època. Mirarem de desvetllar les incògnites que se'ns presentarien de seguir aquesta línia i, en la mesura del nostre enteniment, provarem d'aventurar algunes respostes que considerem caldria implementar.

\subsection{Estructura organitzativa i territorial}

Ambdues dimensions - la funcional i la competencial- que estructuren els serveis socials van molt relacionades en l'actualitat, però les circumstàncies ens indiquen que potser és arribat el moment de repensar-les. La distribució organitzativa entre els serveis bàsics i els serveis especialitzats (fins a cert punt importada de la sanitat) ha servit per apuntalar el

9. Aguilar defineix sistema com "el conjunt organitzat i articulat d'institucions i dispositius que aspiren a respondre a un conjunt de problemes o necessitats socials” (Aguilar, 2009, pág. 173); aquesta articulació, o més aviat la seva manca, és el que porta sovint a dubtar si es tracta d'un veritable sistema. 
repartiment competencial entre les administracions locals (primer les municipals i després també les comarcals) i l'administració autonòmica. Seria convenien analitzar la lògica dels dos àmbits per separat, per mirar que responguin millor als desafiaments del futur.

D’alguna manera, la justificació o criteri que sustenta la diferenciació funcional és que els serveis bàsics (abans d'atenció primària i, en altres llocs, comunitaris o generals) atenen en primera instància tota la població d'una zona territorial determinada, mentre que els serveis especialitzats atenen, per derivació, les situacions més específiques en cada una de les àrees en que s'organitzen, bé per col-lectius (infancia, gent gran, etc.) o problemàtiques (persones amb discapacitat, situacions d'exclusió, etc.). Però, paradoxalment, hi ha serveis per col-lectius concrets en els serveis bàsics, i serveis de proximitat i transversals que consten com especialitzats (Rodríguez Cabrero, 2011, pág. 95).

D'altra banda, les funcions i les prestacions que caldria que formessin part dels serveis socials bàsics no han estat mai discutides a fons, i la legislació actual cau en imprecisions i incoherències que ja fa temps que s'arrosseguen i es denuncien (Col·lectiu de professors/ es de serveis socials, 2008). L'experiència també demostra que sovint es produeixen falles en la interconnexió entre el nivell bàsic i l'especialitzat, podent-se causar interrupcions en la prestació de serveis o destorbs de diversa índole entre ambdós nivells.

El sorgiment de noves necessitats, l'impuls d'una atenció social més centrada en la persona i no tant en els serveis que han d'estar a la seva disposició o, fins i tot, la concatenació gradual dels serveis i llur reversibilitat que són necessaris en alguns àmbits, avalarien també un replantejament ${ }^{10}$. Cal tenir en compte que, l'atenció especialitzada en serveis socials no es pot organitzar en un sol indret o establiment, com passa en el sector sanitari en el qual, majoritàriament, recau en l'hospital de referència, sinó en la dispersió de múltiples nuclis de prestació amb formats diferenciats, la qual cosa complica exponencialment la ineludible concatenació que els caldria tenir com a sistema únic.

Per tant, plantegem si no seria ara el moment de fer-ne una revisió a fons, sota la perspectiva de la nova orientació tractada en el primer epígraf. Aquesta revisió hauria d'intentar respondre a preguntes com: quins són realment els serveis que considerem bàsics per a la cobertura de les necessitats (també bàsiques) que correspondria atendre als serveis socials?

10. S'han fet alguns estudis que aporten evidències en aquest sentit, com en l'àmbit de la salut mental (Pelegri, 2014) 
Com integrem l'atenció més generalista i polivalent amb les funcions més específiques que demanen alguns serveis? Es podrà assegurar la seva prestació amb caràcter universal (i gratuït, com diu l'Estatut d'autonomia de Catalunya de 2006) per totes les persones que els necessitin? I la seva implantació en tot el territori (tant diferenciat) de Catalunya?

Pel que fa a l'estructura territorial i competencial, el sistema dels serveis socials es mou en la dicotomia de proporcionar unes prestacions el màxim d'homogènies possible en tot el territori (per respondre al principi d'igualtat) i, d'altra banda, haver-ho de fer a partir de la confluència d'almenys tres nivells administratius amb competències sobre el sistema i plena autonomia d'actuació. Rodríguez Cabrero es pregunta "Quin és l'equilibri entre la proximitat al ciutadà que ens diu municipalitzem, amb la garantia d'igualtat en tot el territori” (Rodríguez Cabrero, 2010, pág. 238).

La proximitat a les persones exigeix que es pugui respondre de forma amatent des d'instàncies polítiques-administratives també pròximes. En aquest sentit, sembla que l'administració municipal hauria ser la més adequada per organitzar els serveis socials més bàsics però, la quantitat de municipis existents a Catalunya $(947)^{11}$ i l'heterogènia distribució poblacional, fan que aquest criteri resulti insuficient ${ }^{12}$.

Si bé les comarques fan la funció de suplència dels municipis, el seu problema (com el de les diputacions) és que "estan administrades per corporacions d'elecció indirecta, cosa que limita greument el control ciutadà i l'exigència de responsabilitat política" (Aguilar, 2014, pág. 33). A tot plegat cal sumar-hi la Llei 27/2013, de racionalización y sostenibilidad de la Administración Local que, a partir de 2016, podria circumscriure la competència dels serveis socials municipals a la: Evaluación e información de situaciones de necesidad social y la atención inmediata a personas en situación o riesgo de exclusión social (art. 25.2.e) ${ }^{13}$.

A Catalunya, atesa la competència exclusiva de la Generalitat en els serveis socials, l'organització institucional d'aquests s'hauria de basar en un model que fes compatible la igualació en tot allò que cal garantir com a drets subjectius a la població (per tant, essent

11. Idescat [consulta 24-VIII-2015]

12. Només 64 municipis tenen 20.000 o més habitants, 56 en tenen entre 10.001 i 20.000 habitant i la resta menys de 10.000 .

13. Toni Vilà, però, aporta varis arguments avalats per altres experts que demostrarien la no aplicabilitat d'aquesta afectació a Catalunya (Vilà, 2014) 
més estrictes en evitar les desigualtats territorials) i, d'altra banda, la delegació de funcions i la desconcentració de la gestió per garantir la màxima celeritat, implicació i adaptació de les intervencions al territori.

Territori que, tanmateix hauria de reestructurar-se per fer-lo compatible amb les divisions dels altres sectors, especialment els de sanitat i educació, i pensant en la divisió política de que vulgui dotar-se Catalunya en el futur ${ }^{14}$. Potser fora possible prendre com a base un model semblant al de sanitat: centres de primer nivells al menys en cada població que compleixin algun d'aquests requisits: a) que tingui més de 10.000 o 15.000 habitants; b) que sigui cap de comarca; o c) que tingui una posició estratègica que la signifiqui com a nucli de referència per una àrea determinada. I tampoc estaria de més pensar en com, al menys en zones rurals, es podrien crear sinèrgies aprofitant els mateixos establiments per oferir de forma integrada tots els serveis d'atenció a les persones.

\subsection{Complicitat intersectorial}

Seguint el model de Fantova (2014), les polítiques o la coordinació que ell anomena "intersectorials" ${ }^{15}$ podrien significar una major projecció dels serveis socials perquè s'imbricarien en els altres cinc sectors clàssics de l'Estat del benestar. La política intersectorial que té un major grau de consens actualment a Catalunya, és la sociosanitària; la crisi, però, ha evidenciat també possibilitats d'acció en l'àmbit de l'educació, del treball i de l'habitatge que podrien ser més explotades en el futur. En quan a polítiques intersectorials, requeriria un major esforça en l'elaboració de "política conjunta", harmonitzada i sinèrgica entre cadascun dels àmbits i els serveis socials.

Altrament, el que considerem que sempre seria imprescindible establir de forma permanent i efectiva serien les respectives coordinacions intersectorials, cosa que actualment s'ignora majoritàriament o es descuida amb massa freqüència (Rodríguez Cabrero,

14. Aquí tant hi cap el resultat del "procés constituent" que pugui iniciar Catalunya, com les lleis ja aprovades (ex. la de les Vegueries) en el marc de l'estat espanyol.

15. Aquestes es donarien quan hi ha "una certa estructuració explícita de mitjans i fins, una mínima articulació de processos i agents, algun instrument propi netament intersectorial (com una llei o un pla) una relativa governança i gestió comuna dels assumptes en qüestió i alguna instància organitzativa de referència”. Mentre que, quan no s'arriba a formular una política intersectorial, es pot parlar de coordinació intersectorial com "les relacions d'encontre, cooperació, convergència o colllaboració entre sectors" (Fantova, 2014, pág. 357). 
2010, pág. 246). Deixant a banda el nus sociosanitari que ja es perfila com una política intersectorial, seria necessari institucionalitzar en els quatre espais restants, al menys un sistema estable i fort de coordinació intersectorial: socio-educatiu, socio-laboral, socio-habitacional i socio-econòmic.

Per cercar la complicitat intersectorial de què parlem, es podria comptar amb els professionals de "lo social" que hi ha en altres sistemes sectorials del benestar. Trobem, ja ara, professionals amb un marcat perfil social en el sistema sanitari i en el d'ensenyament, i amb menys incidència en l'ocupacional. Fins i tot, hi ha professionals amb aquest perfil en un àmbit que, si bé no forma part dels sis sectors clàssics del benestar, té una connexió estreta amb l'atenció a les persones, com és el sector de la justícia en les seves respectives vessants: assessorament a l'entramat judicial, intervenció en institucions de reclusió i programes de reinserció social.

El que hi ha de comú en aquests professionals és que estan enquadrats en sistemes o sectors que tenen el seu propi bé a protegir (la salut, l'aprenentatge, l'ocupabilitat, etc.). Una de les funcions en aquests sectors dels professionals de "lo social" consisteix en detectar i/o avaluar les necessitats de caràcter social que sorgeixen en el curs de l'atenció pròpia del sistema on treballen, i en posar en relació les persones que tenen dites necessitats amb les activitats $\mathrm{i}$ instruments propis dels serveis socials que els hi poden oferir una resposta pertinent. Són figures/equips que, al menys en part, fan de pont, atesa la inqüestionable relació que hi ha entre els sectors de les polítiques socials.

Sovint s'ha debatut quina seria la ubicació més adequada d'aquests professionals. Val a dir que els implicats acostumen a ser acèrrims defensors de seguir en els sistemes als què estan adscrits. Això és així perquè saben com d'important és la perspectiva social i tenen molt clar que aporten respostes socials a uns sistemes sectorials als que, precisament, els manca aquesta vessant ja què treballen per un altre objecte. Això no treu però, que els sabers disciplinaris respectius, els permetin connectar millor amb els recursos socials.

Aquest paper de frontissa, no obstant, no s'ha vetllat massa des dels serveis socials. El sistema que exerceix la dependència orgànica (aquell on consten en plantilla) s'ha cuidat de marcar-los-hi les funcions que necessitava per complementar el seu objecte primordial, mentre el sistema de serveis socials no ha ofert a aquells professionals de "lo social" un adequat acompanyament per la part de dependència funcional que els pot vincular. 
Tenint en compte això, entenem que hi podria haver dos fronts on seria convenient avançar: a) en acabar d'omplir aquests nusos d'interacció dels altres sectors i sistemes que no els disposen o en els que encara són escassos i febles; i b) en consolidar i completar degudament el paper de frontissa dels professionals i equips ja existents, per assegurar una més efectiva coordinació amb els serveis socials.

Pel que fa al primer aspecte, caldria promocionar les funcions que podrien fer els professionals de "lo social" en els sectors o sistemes d'habitatge, de treball i de rendes. Aquests sectors són els que menys s'han distingit per realitzar una intervenció directa amb les persones. La seva activitat ha estat, al menys fins ara, merament burocràtica, però per arribar a fer una política que millori la vida de la gent, no es pot obviar el tractament personal com a element cabdal de la cobertura de llurs necessitats.

No hauria de succeir que "un afectat per un desnonament pot preferir, arribat el cas, una organització ciutadana [com la Plataforma d'Afectats per la Hipoteca] abans que la institució corresponent que hauria d'ajudar-lo a vetllar pels seus drets" ens diuen Subirats i Vallespín (2015, pág. 74). Seria pertinent que, per exemple, el sector de l'habitatge disposés de més professionals de "lo social" per realitzar l'atenció personalitzada a les famílies que preveuen perdre o ja han perdut el seu habitatge, analitzar com és la seva necessitat d'allotjament i proporcionar-los-hi els ajuts del propi sistema. El mateix es podria aplicar al sistema de treball per acompanyar els processos d'inserció laboral, o al de manteniment de la renda on seria necessari disposar de professionals socials per fer les pertinents valoracions i seguiments dels potencials beneficiaris ${ }^{16}$.

El segon front passaria per aprofundir aquelles línies polítiques que fossin més necessaries en cadascun d'aquests nodes intersectorials per tal de vincular-los funcionalment als serveis socials. Els professionals de "lo social" del sistema d'educació, en cada territori haurien de participar des de la planificació dels serveis socials per infants fins a les iniciatives que es poguessin incardinar en la formació d'adults. I, al mateix temps, rebre la informació de serveis socials que els fos necessària per abordar les necessitats o problemàtiques que apareixen en l'entorn escolar. El mateix es podria desenvolupar per a la resta de sistemes on s'implantessin els professionals de "lo social".

16. El Col-legi de Treball Social diu sobre els drets socials que "no formen part dels serveis socials les funcions que corresponen a d'altres sistemes (salut, educació, habitatge, etc.), especialment les referides a la determinació de la situació econòmica i social, que s'han de dur a terme des de cadascun dels sistemes, amb indicadors i criteris comuns i coordinats" (Col-legi Oficial de Treball Social de Catalunya, 2015). 


\subsection{Prestacions i cartera de serveis}

En definitiva, on es legitima o es desacredita un sistema, és en l'assortiment, suficiència i qualitat de les prestacions que ofereix als ciutadans en el seu camp de competència. Si bé és cert que la capacitat prestacional no s'improvisa d'un dia per altre, després de 35 anys d'implantació dels serveis socials a Catalunya potser caldria esperar una major grau de maduresa i racionalització en aquest aspecte.

$\mathrm{El}$ sistema de serveis socials es materialitza en un conjunt de prestacions, que poden ser de servei (tècniques-professionals), econòmiques o tecnològiques. Les prestacions de servei es complementen amb elements materials, doncs si bé algunes es proporcionen en l'habitatge de l'usuari o es dispensen en un establiment d'atenció ambulatòria, moltes altres precisen d'establiments diürns o establiments residencials (siguin habitatges amb distints nivells de supervisió o centres especials amb diferents dosis d'intensitat assistencial). Però a partir d'aquí, poques coses més s'ha avançat amb prou rigor i claredat sobre elles.

Les prestacions de servei són les més nombroses i també les més difícils de conceptualitzar. Tant s'inscriu com a prestació el "servei d'orientació" com un "servei residencial". Això planteja la qüestió de si és igual una funció i un servei, o si un servei es pot basar en una única funció mentre en d'altres és a la inversa. O quin és el grau de concreció-amplitud d'una prestació per no caure en el bucle d'una prestació que n'inclou una altra,i aquesta segona una tercera, etc. Cabria plantejar si no hi ha una certa inflació de prestacions amb pocs criteris de diferenciació entre algunes d'elles.

Respecte a les prestacions econòmiques, tal com avançàvem, caldria pensar en la possibilitat de concentrar la gran diversitat que n'hi ha i/o fer-les dependre en sa majoria del sector de garantia d'ingressos (unificat o no en la institució de la Seguretat social, i sigui responsabilitat de l'Estat espanyol o d'una futura Agència Catalana de Protecció Social). Si es fes refonent les formes actuals de provisió d'ingressos en una única prestació econòmica (tipus Renda Garantida de Ciutadania o tipus Renda Bàsica Universal) ${ }^{17}$, seria

17. Rodríguez Cabrero també veu possible estendre la renda activa d'inserció (RAI) com a base d'una protecció universal (Rodríguez Cabrero, 2010). 
més facil i coherent abordar la cobertura de les necessitats bàsiques assegurant la dignitat i limitant el paternalisme amb que s'actua en el present.

Es podria igualment considerar si, a part de les prestacions econòmiques incondicionals, haurien de seguir existint altres prestacions econòmiques que apuntessin a compensar el sobre-cost que experimenten determinades persones a causa de posseir trets diferencials, personals o familiars, com la diversitat funcional o la dependència. Aquestes prestacions finalistes podrien dependre o estar gestionades pel sector de serveis socials atesa l'estreta relació que hi ha entre el bé a protegir del que s'ha parlat supra i els mitjans econòmics imprescindibles per assolir-lo.

Pel que fa a les prestacions dites tecnològiques, un anàlisi inclús superficial permet veure el desgavell que existeix en la seva tipologia actual. La llei de serveis socials les defineix com "les que per mitjà d'un producte atenen necessitats socials de la persona” (art. 23). Un exemple seria la teleassistència domiciliària, la qual però, en la cartera de serveis socials 2010-2011 consta com a prestació de servei dins els serveis bàsics: servei de les tecnologies de suport $i$ cura. De nou ens trobem amb defectes de definició i ubicació racionals.

Considerant la definició anterior, haurien de ser considerades prestacions tecnològiques el servei de transport adaptat i qui sap si també el telèfon de la infancia i la línia d'atenció a les dones en situació de violència masclista, totes elles incloses com a serveis. D'altra banda, algunes de les que consten com a prestacions tecnològiques, semblen ser, més aviat, aportacions en diners (per a la compra d'aparells o per reformes d'adaptació d'habitatges) que serien més pròpies de les prestacions econòmiques. En aquest tipus de prestacions, als serveis socials els queda molt recorregut encara, i caldria esperonar molt més els ajuts d'I+D+i per descobrir aplicacions tecnològiques que milloressin l'atenció personal en aquest camp.

Un darrer element que caldria repensar, gairebé diria que independentment de si s'assumeix o no la nova orientació que estem desenvolupant, és la cartera de serveis. Es tracta d'una eina molt important perquè desenvolupa la llei i és imprescindible per assolir una plena garantia dels drets subjectius. Però aquesta importància no s'hauria de veure 
minorada per determinades qüestions de fons i de forma. I ens temem que així ha succeït en les dues versions de cartera de serveis que hem tingut fins ara ${ }^{18}$.

La cartera de serveis socials és molt extensa per dues raons bàsiques. Primer, perquè sembla estar confeccionada per la suma de tots els serveis (o quasi) existents en el seu moment sense seleccionar aquells que realment es podien assumir i garantir per al conjunt de la població catalana. I segon, perquè de molts serveis, se'n va voler especificar unes diferències irrellevants en quant a naturalesa, i això va comportar inscriure'ls com a serveis diferents sense ser-ho realment ${ }^{19}$.

Les carteres, com diu Vilà són "detallistes i amb serioses confusions entre equipaments, centres, prestacions i serveis" la qual cosa el porta a concloure que "poden contribuir a consolidar un model burocràtic i reglamentarista de serveis socials [...] haurien de buscar-se instruments flexibles i àgils que recollissin serveis i prestacions amplis que, d'una banda, permetessin ajustar-se a les necessitats personals i familiars i que, d'altra banda, fossin compatibles amb les exigències jurídiques dels drets subjectius reconeguts" (Vilà, 2011, pág. 179).

Per concloure, tant les prestacions com la cartera de serveis que els inclou, tot i representar un important avenç en el desenvolupament del sistema, ha quedat lluny de contribuir a l'objecte o bé a protegir dels serveis socials que en aquest treball hem intentat posar al centre del debat. La cartera hauria de ser una eina dinàmica i operativa, que simplifiqués el quadre de prestacions tot i admetent en cadascuna les adaptacions a l’àmbit o circumstància que fossin necessàries aplicar. I sobretot, progressiva en l'ampliació i implantació de les prestacions, alhora que vinculant en quant als drets subjectius que s'ho garanteixen.

18. La del 2008-2009 (Decret 151/2008, de 29 de juliol, pel qual s'aprova la Cartera de serveis socials 2008-2009) i la de 2010-2011 (Decret 142/2010, d'11 d'octubre, pel qual s'aprova la cartera de serveis socials 2010-2011). Aquesta última, és la segueix prorrogada cinc anys després.

19. Per exemple, entre el Servei de centre de dia de teràpia ocupacional (STO) per a persones amb discapacitat intel·lectual i el Servei de centre de dia de teràpia ocupacional (STO) per a persones amb discapacitat intel-lectual, amb auxiliar. En els serveis per persones amb discapacitat es repeteixen molts serveis amb l'única diferència del tipus de discapacitat que es tracti: intel-lectual o física. 


\section{Conclusions}

Com a resultat de l'estudi i la reflexió argumentada que hem realitzat, se'n poden extreure algunes conclusions que responen al que preteníem plantejar: la necessitat de repensar la política de serveis socials dins el marc de l'Estat del benestar per fer front als nous temps que se'ns presenten.

Aquest replantejament creiem que té dos fronts d'acció, entorn dels quals hem desgranat el discurs precedent. D'una banda, i des del marc constitutiu, caldria emprendre una revisió de la naturalesa dels serveis socials per tal de corregir certes mancances que arrosseguen des de la seva gènesi constitucional. I de l'altra, la vessant més pràctica, hi ha la necessitat inajornable de repensar com els serveis socials haurien afrontar els reptes que es plantegen a partir del canvi d’època que s'albira.

En el primer front, s'ha defensat que l'enfortiment dels serveis socials esdevé condicionat a que se li apliquin un seguit de mesures de caire estructural. Entre aquestes, aquí s'han evidenciat com a prioritàries: 1) la remodelació dels serveis socials en un sector de cobertura universal per a que es converteixi realment en el "quart pilar" del benestar; 2) la redefinició del seu objecte de treball més d'acord amb la funció social que li correspon, amb la consegüent descàrrega de les funcions que li són inadequades; i 3) el blindatge del dret subjectiu de que es dotin certs serveis socials i que, d'acord amb el model autonòmic existent, pugui crear cada comunitat autònoma d'acord amb les seves prioritats.

Pel que fa a la segona línia argumental, centrada en donar el sentit i l'impuls que requeririen els serveis socials de la nova època, conclouríem assenyalant també tres constatacions acompanyades d'algunes propostes: 1) la necessitat d'emprendre una harmonització de l'estructura funcional dels serveis socials així com de l'estructura territorial adoptada, per a superar les incoherències i entrebancs existents en i entre ambdues; 2) plantegem explorar els espais intersectorials de l'Estat del benestar, tot i aprofitant la valuosa presència de professionals de "lo social" que hi ha, i que encara pot estendre's més, en alguns sectors; i 3) el nivell més operatiu del sistema, que es materialitza en la seva cartera de prestacions, presenta disfuncionalitats que li fan perdre utilitat i eficàcia per a la missió que el sistema de serveis socials té encomanada $i$, per tant, caldria renovar-la dotant-la de major racionalitat i coherència. 


\section{Bibliografia}

Aguilar, M. (2009). "Servicios sociales: Las tribulaciones de un sector emergente”. En L. Moreno (ed.), Reformas de las politicas del bienestar en España (págs. 171-205). Madrid: Siglo XXI.

Aguilar, M. (2013). "Los servicios sociales en la tormenta”. Documentación Social, 166, $145-167$.

Aguilar, M. (2014). “Apuntes para un replanteamiento de los servicios sociales en España”. En VII Informe sobre exclusión y desarrollo social en España 2014 (documento de trabajo 5.12). Madrid: Fundación FOESSA.

Añon, M., \& García, J. (2004). Lecciones de derechos sociales. Valencia: Tirant lo Blanch.

Col-lectiu de professors/es de serveis socials. (2008). "Una mirada a punts crítics de la nova Llei de Serveis Socials". Revista de Treball Social RTS, 183, 87-97.

Col-legi Oficial de Treball Social de Catalunya. (26 de agost de 2015). La constitucionalització dels drets socials. Obtenido de http://www.tscat.cat/.

Decret 142/2010, d'11 d'octubre, pel qual s'aprova la cartera de serveis socials 2010-2011. (Diari Oficial de la Generalitat de Catlunya no 5738 de 20 d'octubre).

Decret 151/2008, de 29 de juliol, pel qual s'aprova la Cartera de serveis socials 2008-2009. (Diari Oficial de la Generalitat de Catalunya no 5185 de 31 de juliol.

Fantova, F. (2014). Diseño de politicas sociales. Fundamentos, estructuras y propuestas. Madrid: CCS.

Generalitat de Catalunya. (2015). Mapa de prestacions socials de Catalunya. Barcelona: Generalitat de Catalunya.

Pelegri, X. (2014). “Análisis de la red de servicios sociales en el sector de las personas con problemática de salud mental”. Trabajo Social y Salut, 79, 7-21.

Rodríguez Cabrero, G. (2010). "Crisis y mecanismos de garantia de rentas: desempleo, seguridad social, rentas mínimas de inserción y servicios sociales". Revista del Ministerio de Trabajo e Inmigración, número extraordinario, 235-247.

Rodríguez Cabrero, G. (2011). Servicios sociales y cohesión social. Madrid: Consejo Económico y Social.

Santos, J. (2012). El cuarto pilar. Un nuevo relato para los servicios sociales. Madrid: Paraninfo/Consejo General de Trabajo Social.

Subirats, J., \& Vallespín, F. (2015). España/Reset. Herramientas para un cambio de sistema. Barcelona: Ariel. 
Vilà, A. (2011). Tendencias en la nueva legislación de los servicios sociales. Madrid: European Anti Poverty Network.

Vilà, A. (2014). "La reforma local y su impacto en los servicios sociales". Servicios Sociales y Politica Social, 106, 25-47. 
Xedagogia i Treball Social

Revista de Ciències Socials Aplicades

Edita: Universitat de Girona

Disseny i maquetació: info@clam.cat · 647427732

Dipòsit Legal: GI.904-2010

ISSN: 2013-9063 